This is an electronic reprint of the original article. This reprint may differ from the original in pagination and typographic detail.

Author(s): Caputo, Christine; Koivistoinen, Juha; Moilanen, Jani; Boynton, Jessica; Tuononen, Heikki; Power, Philip

Title: $\quad$ Counterintuitive Mechanisms of the Addition of Hydrogen and Simple Olefins to Heavy Group 13 Alkene Analogues

Year: $\quad 2013$

Version:

Please cite the original version:

Caputo, C., Koivistoinen, J., Moilanen, J., Boynton, J., Tuononen, H., \& Power, P. (2013). Counterintuitive Mechanisms of the Addition of Hydrogen and Simple Olefins to Heavy Group 13 Alkene Analogues. Journal of the American Chemical Society, 135(5), 1952-1960. https://doi.org/10.1021/ja3116789

All material supplied via JYX is protected by copyright and other intellectual property rights, and duplication or sale of all or part of any of the repository collections is not permitted, except that material may be duplicated by you for your research use or educational purposes in electronic or print form. You must obtain permission for any other use. Electronic or print copies may not be offered, whether for sale or otherwise to anyone who is not an authorised user. 


\title{
Counterintuitive Mechanisms of the Addition of Hydrogen and Simple Olefins to Heavy Group 13 Alkene Analogues.
}

\author{
Christine A. Caputo, Juha Koivistoinen, ${ }^{\dagger}$ Jani Moilanen, ${ }^{\dagger}$ Jessica N. Boynton, Heikki M. \\ Tuononen, ${ }^{* \dagger}$ and Philip P. Power* \\ Department of Chemistry, the University of California Davis, 1 Shields Ave., Davis, CA \\ 95616, United States. \\ $\dagger$ Department of Chemistry, University of Jyväskylä, P.O. Box 35, FI-40014 Jyväskylä, \\ Finland.
}

KEYWORDS cycloaddition, aluminum, gallium, ethylene, hydrogen, low-coordinate, group 13, terphenyl ligand, density functional theory

\begin{abstract}
The mechanism of the reaction of olefins and hydrogen with dimetallenes $\operatorname{ArMMAr}(\mathrm{Ar}=$ aromatic group; $\mathrm{M}=\mathrm{Al}$ or $\mathrm{Ga})$ was studied by density functional theory calculations and experimental methods. The digallenes, for which the most experimental data are available, are extensively dissociated to gallanediyl monomers :GaAr in hydrocarbon solution, but we found that they do not react as the more open dissociated species. Instead, the calculations and experimental data show that they react with simple olefins such as ethylene as intact ArGaGaAr dimers via two stepwise $[2+2]$ cycloadditions due to their considerably lower activation barriers vis-à-vis the gallanediyl monomers, :GaAr. This mechanism was preferred over the $[2+2]$ cycloaddition of ethylene to a monomeric :GaAr to form a gallacyclopropane ring which could in principle then dimerize to form the 1,2-digallacyclobutane intermediate and, subsequently, the 1,4digallacyclohexane product. In addition, calculations show that the addition of $\mathrm{H}_{2}$ to digallene proceeds by a different mechanism involving the initial addition of one equivalent of $\mathrm{H}_{2}$ to form a 1,2-dihydride intermediate. This reacts with a second equivalent of $\mathrm{H}_{2}$, to give two $\mathrm{ArGaH}_{2}$ fragments which recombine to give the observed product with terminal and bridging $\mathrm{H}$-atoms, $\mathrm{Ar}(\mathrm{H}) \mathrm{Ga}(\mu-\mathrm{H})_{2} \mathrm{Ga}(\mathrm{H}) \mathrm{Ar}$.
\end{abstract}


The computational findings are in agreement with experimental observations that the digallene $\mathrm{Ar}^{\mathrm{iPr}{ }_{4}} \mathrm{GaGaAr}^{\mathrm{iPr}{ }_{4}}\left(\mathrm{Ar}^{\mathrm{iPr} \mathrm{Pr}_{4}}=\mathrm{C}_{6} \mathrm{H}_{3}-2,6-\left(\mathrm{C}_{6} \mathrm{H}_{3}-2,6-{ }^{i} \mathrm{Pr}_{2}\right)_{2}\right)$, reacts readily with two equivalents of olefin or hydrogen to give 1-4-digallacyclohexane or aryl gallium dihydride products, whereas the stable monomer, : $\mathrm{GaAr}^{\mathrm{iPr} 8}\left(\mathrm{Ar}^{\mathrm{iPr} 8}=\mathrm{C} 6 \mathrm{H}-2,6-\left(\mathrm{C}_{6} \mathrm{H}_{3}-2,4,6-\right.\right.$ $\left.{ }^{i} \operatorname{Pr}_{3}\right)_{2}-3,5-{ }^{i} \operatorname{Pr}_{2}$ ), does not react with ethylene or hydrogen. Calculations on the reaction of propene to ArAlAlAr show that, in contrast to the digallenes, addition involves an openshell transition state consistent with the higher singlet diradical character of dialuminenes.

\section{INTRODUCTION}

The activation of hydrogen and other small molecules by main group compounds under ambient conditions is currently an area of burgeoning interest. In 2005 we reported the activation of hydrogen by a heavy group 14 element alkyne analogue, digermyne, under ambient conditions. ${ }^{1}$ This was followed shortly thereafter by the advent of frustrated Lewis pair chemistry of Stephan, in which hydrogen activation also proceeds under ambient conditions. ${ }^{2}$ The activation of hydrogen by Bertrand's cyclic alkylaminocarbenes $^{3}$ and this group's heavier group 14 element dimetallynes has also been reported. ${ }^{4}$ Recently, a digermyne with a single Ge-Ge bond was found to activate hydrogen in the solid state by Jones and coworkers. ${ }^{5}$

Numerous workers have reported computational insights into the mechanism of transition metal-free hydrogen activation. ${ }^{6}$ Notably, a recent study by Schleyer, Wang, and coworkers examined in detail the mechanisms for the reaction of the group 14 alkyne analogues, digermyne and distannyne, with hydrogen by density functional theory (DFT), and concluded that different products were obtained as a result of the greater stability of the tin +2 oxidation state. $^{7}$

Our initial synthesis of a neutral heavy group $13^{8}$ alkene analogue, $\mathrm{Ar}^{\mathrm{iPr}{ }_{4}} \mathrm{GaGaAr}^{\mathrm{iPr} 4}$ $\left(\mathrm{Ar}^{\mathrm{iPr}}{ }^{\mathrm{Pr}_{4}}=\mathrm{C}_{6} \mathrm{H}_{3}-2,6-\left(\mathrm{C}_{6} \mathrm{H}_{3}-2,6-{ }^{i} \mathrm{Pr}_{2}\right)_{2}\right)$, showed that the Ga-Ga bond distance was quite long (2.6268(7) $\AA$ ). ${ }^{9}$ Previous computational studies have elucidated the nature of the bonding in $\mathrm{Ar}^{\mathrm{iPr}}{ }_{4} \mathrm{GaGaAr}^{\mathrm{iPr}_{4}}{ }^{10}$ and related group 13 metal species substituted by a variety of terphenyl and other ligands. ${ }^{10,11}$ The calculations showed that the Ga-Ga bonds are weak 
and their bond enthalpies did not exceed $c a .50 \mathrm{~kJ} \mathrm{~mol}^{-1}$. These results were in agreement with electronic spectroscopy and cryoscopic measurements which showed that in hydrocarbon solution, dissociation to : $\mathrm{GaAr}^{\mathrm{iPr}}{ }^{\mathrm{P}}$ monomers was extensive. ${ }^{9,10}$ By increasing the steric bulk of the terphenyl ligand, a monomeric gallium species :GaAr ${ }^{\mathrm{iPr}}{ }^{8}$ $\left(\mathrm{Ar}^{\mathrm{iPr}}{ }^{\mathrm{Pr}_{8}}=\mathrm{C}_{6} \mathrm{H}-2,6-\left(\mathrm{C}_{6} \mathrm{H}_{2}-2,4,6-{ }^{i} \mathrm{Pr}_{3}\right)_{2}-3,5-{ }^{i} \mathrm{Pr}_{2}\right)$ could be isolated in the solid state and structurally characterized (Scheme 1). ${ }^{10}$

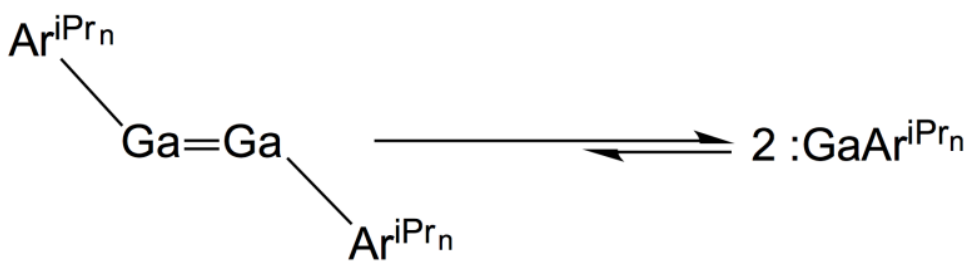

\section{Scheme 1. Digallene dimer-monomer equilibrium.}

In solution the gallanediyl monomer/digallene equilibrium mixture was shown to react readily and cleanly with hydrogen (and ammonia) under ambient conditions. ${ }^{12}$ The presence of monomeric : GaAr as the major species in solution together with its lower steric crowding in comparison to its dimer ArGaGaAr strongly suggested that it could be intimately involved in the addition reaction of hydrogen owing to the lower degree of steric hindrance at the metal. Unlike the reactions of the analogous Group 14 heavy alkyne analogue of germanium ${ }^{1}$ which gives a mixture of multiple addition products, the reaction of $\mathrm{Ar}^{\mathrm{iPr} 4} \mathrm{GaGaAr}^{\mathrm{iPr} 4}$ with hydrogen gives a single product in which two bridging hydrides and a terminal hydride are found at each gallium (Scheme 2).

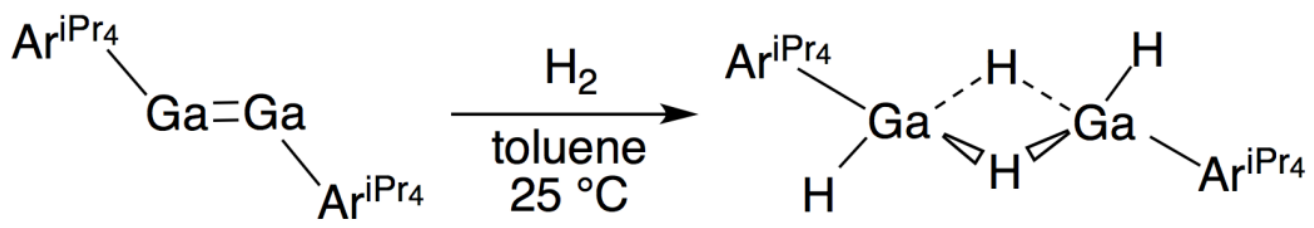

\section{Scheme 2. Reaction of digallene with hydrogen.}

Subsequent reactivity studies revealed that the digallene $\operatorname{Ar}^{\mathrm{iPr}{ }_{4}} \mathrm{GaGaAr}^{\mathrm{iPr}{ }_{4}}$ also reacts instantaneously under ambient conditions with simple olefins (ethylene, propene, 1hexene and styrene). ${ }^{13}$ The product isolated from the reaction of these olefins contained a 1,4-digallacyclohexane core and is believed to result from a $[2+2+2]$ cycloaddition 
reaction (Scheme 3). ${ }^{14}$ Treatment of $\mathrm{Ar}^{\mathrm{iPr}{ }^{\mathrm{Pr}}} \mathrm{GaGaAr}^{\mathrm{iPr} 4}$ with internal olefins did not result in any reaction, indicating that the system is highly sensitive to the steric environment.

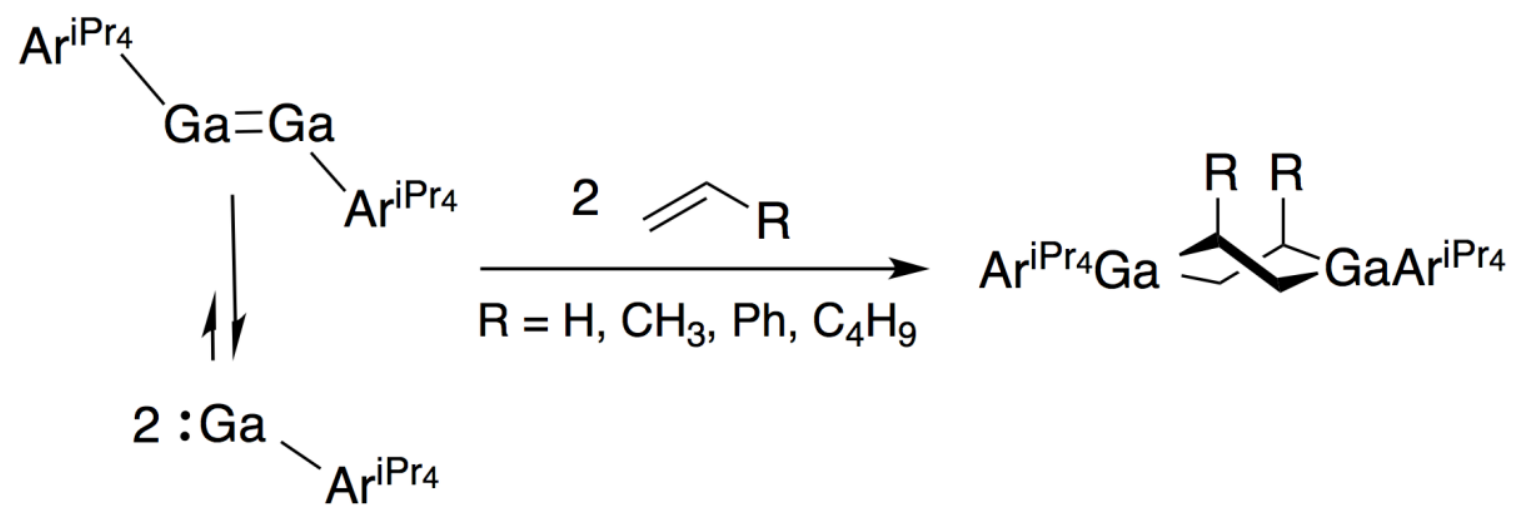

\section{Scheme 3. Addition of simple terminal olefins to the equilibrium mixture of digallene and monomeric gallanediyl.}

We now show that DFT calculations provide significant computational insight into the mechanism of addition of olefins and hydrogen to the heavy alkene congener $\mathrm{Ar}^{\mathrm{iPr}{ }_{4}} \mathrm{GaGaAr}^{\mathrm{iPr_{4 }}}\left(\mathrm{Ar}^{\mathrm{iPr}_{4}}=\mathrm{C}_{6} \mathrm{H}_{3}-2,6-\left(\mathrm{C}_{6} \mathrm{H}_{3}-2,6-{ }^{i} \mathrm{Pr}_{2}\right)_{2}\right)$. By using a set of suitable model systems, we demonstrate that the most plausible mechanism for these reactions involves a stepwise double $[2+2]$ cycloaddition to the digallene and that the involvement of monomeric gallanediyls in transformations is unlikely due to unfavorable activation and reaction energies. We also show experimentally that the sterically hindered gallanediyl :GaAri ${ }^{\mathrm{Pr}}$, which does not associate to a digallene, displays no reactivity with ethylene or hydrogen under ambient conditions.

With regard to dialuminenes, computational data on the dimetallenes RMMR $(M=A l$, $\mathrm{Ga}, \mathrm{In}, \mathrm{Tl} ; \mathrm{R}=\mathrm{H}, \mathrm{Me}, \mathrm{Bu}^{\mathrm{t}}, \mathrm{Ph}$ ) have suggested that there is an important singlet diradical component in their bonding that is highest in the aluminum species and diminishes as the group is descended. ${ }^{11,15}$ Our calculations on the addition of propene to the model species $\operatorname{ArAlAlAr}\left(\mathrm{Ar}=\mathrm{C}_{6} \mathrm{H}_{3}-2,6-\mathrm{Me}_{2}\right)$ show that, in contrast to the digallene, it proceeds via an open-shell transition state involving a dangling $\mathrm{CH}_{3}-\mathrm{C}(\mathrm{H})-\mathrm{CH}_{2}-$ moiety with unpaired spin density on an aluminum atom consistent with the higher diradical character of the dialuminene. 


\section{EXPERIMENTAL}

General Procedures. All manipulations were carried out under anaerobic and anhydrous conditions. All reagents were trap-to-trap vacuum distilled and dried over $4 \AA$ molecular sieves prior to use. : $\mathrm{GaAr}^{\mathrm{iPr}{ }_{8}}(\mathbf{1})$ was prepared according to literature procedures. ${ }^{10}{ }^{1} \mathrm{H}$, ${ }^{13} \mathrm{C}\left\{{ }^{1} \mathrm{H}\right\}$ NMR spectra were recorded on Varian spectrometers and referenced to known standards.

Reaction of :GaAriPrs with ethylene. The monomer : $\operatorname{GaAr}^{\mathrm{iPr} 8}(0.20 \mathrm{~g}, 0.32 \mathrm{mmol})$ was dissolved in $10 \mathrm{~mL}$ of dry pentane to give an amber solution. The headspace of the Schenk flask was purged with ethylene and kept under a constant pressure of ethylene for $6 \mathrm{~h}$. The Schlenk was then sealed and stirred overnight (18 h) under ambient conditions. The color of the solution remained unchanged. The solvent was removed under reduced pressure. ${ }^{1} \mathrm{H}$ NMR showed no evidence of the formation of olefin addition, and the : $\mathrm{Ga}^{\mathrm{iPr} 8}$ could be recovered unchanged.

Reaction of :GaAr ${ }^{\mathrm{PPr}_{8}}$ with hydrogen. : $\mathrm{GaAr}^{\mathrm{iPr_{8 }}}(0.06 \mathrm{~g}, 0.09 \mathrm{mmol})$ was dissolved in 10 $\mathrm{mL}$ of dry pentane to give an amber solution. The headspace of the Schlenk flask was purged with hydrogen and kept under a constant pressure of hydrogen for $15 \mathrm{~min}$. The Schenk was then sealed and stirred overnight ( $18 \mathrm{~h}$ ) under ambient conditions. The color of the solution remained unchanged. The solvent was removed under reduced pressure. ${ }^{1} \mathrm{H}$ NMR spectroscopy of the residue $(0.06 \mathrm{~g})$ in $\mathrm{C}_{6} \mathrm{D}_{6}$ showed that the spectrum of $: \mathrm{GaAr}^{\mathrm{iPr} 8}$ was unchanged, with no trace of $\mathrm{Ga}-\mathrm{H}$ signals in the spectrum.

Computational Details: All geometry optimizations were conducted with DFT using the PBE0 hybrid density functional ${ }^{16}$ and Ahlrich's TZVP basis sets. ${ }^{17}$ Frequency calculations were carried out for detected stationary points to ensure that they correspond to either true minima (no imaginary frequencies) or to first order transition states (only one negative imaginary frequency) on the potential energy hypersurface. The singlet diradical nature of the investigated transition states was assessed by conducting broken symmetry calculations in which the spatial parts of the $\alpha$ and $\beta$ spin electrons are allowed to differ in order to simulate static correlation effects. ${ }^{18}$ All calculations were performed with the 
Gaussian09 program, ${ }^{19}$ whereas orbital visualizations were generated with gOpenMol $3.0 .^{20}$

\section{RESULTS AND DISCUSSION}

We have previously shown that the digallene $\mathrm{Ar}^{\mathrm{iPr}{ }^{\mathrm{Pr}}} \mathrm{GaGaAr}^{\mathrm{iPr}}{ }^{\mathrm{P}}$ reacts readily under ambient conditions with ethylene and other terminal olefins (propene, 1-hexene and styrene) to give the addition of two equivalents of the olefin across the digallene and exclusive formation of a $[2+2+2]$ cycloaddition product (see Scheme 3). ${ }^{13}$ The Ga-Ga bond was cleaved in all cases and structures containing a 1,4-digallacyclohexane core were obtained. More recently, we reported that the same digallene acts as a true alkene analogue in cycloaddition reactions with cyclic polyolefins which possess conjugated alkenes. ${ }^{21} \mathrm{~A}$ Ga-Ga bond was maintained in most cases after reaction of $\mathrm{Ar}^{\mathrm{iPr}_{4}} \mathrm{GaGaAr}{ }^{\mathrm{Pr}_{4}}$ with cycloheptatriene (CHT), cyclopentadiene $(\mathrm{CpH})$ or norbornadiene (NBD) along with the presence of two 'GaAr' equivalents in the isolated structures.

There are two mechanistic pathways leading to the $[2+2+2]$ cycloaddition product, which do not involve radical type reactivity (Scheme 4). In the first instance, a single equivalent of olefin adds in a [2+2] fashion across the formal $\mathrm{Ga}=\mathrm{Ga}$ double bond to form a 1,2-digallacyclobutane intermediate, which then can add another equivalent of olefin in the same manner, breaking the Ga-Ga single bond and forming the 1,4digallacyclohexane product. The second pathway implicates the :GaAr ${ }^{\mathrm{iPr} 4}$ monomer which reacts with the olefin in $\left[2_{\pi}+2_{\sigma}\right]$ manner to form a gallacyclopropane intermediate, which can then react either with another equivalent of : $\mathrm{GaAr}^{\mathrm{iPr}_{4}}$ monomer to form 1,2-digallacyclobutane or with a second gallacyclopropane intermediate to form the product. Despite being unable to observe radical intermediates in the reaction mixture experimentally, a third pathway involving an initial stepwise addition of olefin to the digallene $\mathrm{Ar}^{\mathrm{iPr} 4} \mathrm{GaGaAr}^{\mathrm{iPr} 4}$ cannot be unequivocally ruled out. 


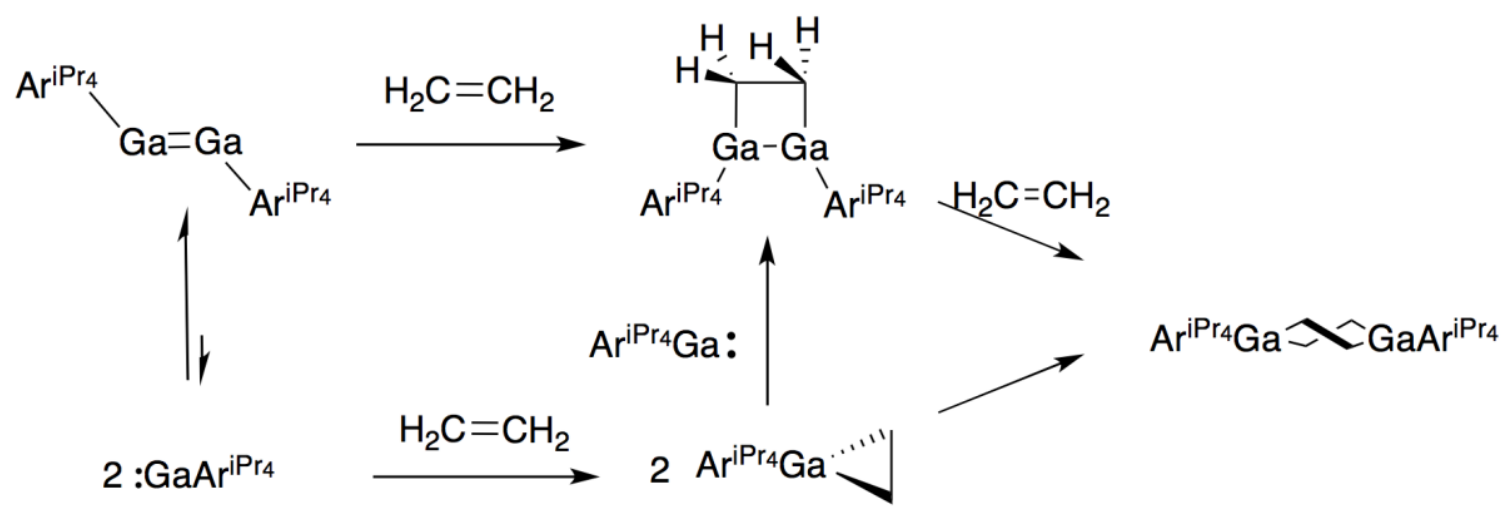

Scheme 4. Proposed mechanistic pathways for the reaction of digallene with simple terminal olefins.

Experimentally, products containing gallacyclopropane were never observed spectroscopically or isolated from the reaction of $\mathrm{Ar}^{\mathrm{iPr}}{ }_{4} \mathrm{GaGaAr} \mathrm{Pr}_{4}$ with terminal olefins, which supports the proposal that the digallene is the sole reactive species. We note, however, that analogous $\left[2_{\pi}+2_{\sigma}\right]$ cycloaddition structures have been seen in several other systems of low-coordinate low-valent main group complexes. Specifically, silylenes and germylenes have shown significant reactivity in $\left[4_{\pi}+2_{\sigma}\right]$ and $\left[2 \pi+2_{\sigma}\right]$ cycloadditions. $^{22}$ In contrast, we did not observe the formation of any $[n+2 \sigma]$ cycloaddition products when $\mathrm{Ar}^{\mathrm{iPr}}{ }_{4} \mathrm{GaGaAr}^{\mathrm{iPr}}{ }_{4}$ was reacted with either terminal olefins or cyclic polyolefins.

Orbital considerations. We began our investigations on the mechanism of the reaction of digallenes with terminal olefins by examining the morphologies of their key frontier orbitals (Figures 1 and 2). It is immediately apparent that the interaction of the HOMO of ethylene with the LUMO of trans-bent digallene (Figure 1) is symmetry allowed and favorable, implying reactivity between the two species (unlike in the corresponding all carbon systems, where a thermal $[2 \pi+2 \pi]$ cycloaddition is forbidden because of the $\pi-\pi^{*}$ symmetry mismatch). In contrast, the inverse interaction of the HOMO of trans-bent digallene with the LUMO of ethylene is not preferred due to poor spatial overlap of the orbital lobes. If we consider that the digallene isomerizes to a cis-conformation, both the calculated HOMO and LUMO of cis-digallene have proper symmetry and shape to react with the LUMO and HOMO of ethylene, respectively (Figure 1). Calculations for the 
frontier orbitals of the resulting 1,2-digallacyclobutane intermediate confirm the presence of these interactions in its HOMO and HOMO-1 orbitals; the LUMO of 1,2digallacyclobutane is essentially that of trans-digallene i.e. an out-of-plane $\pi$-type orbital which is bonding between the two Ga atoms.

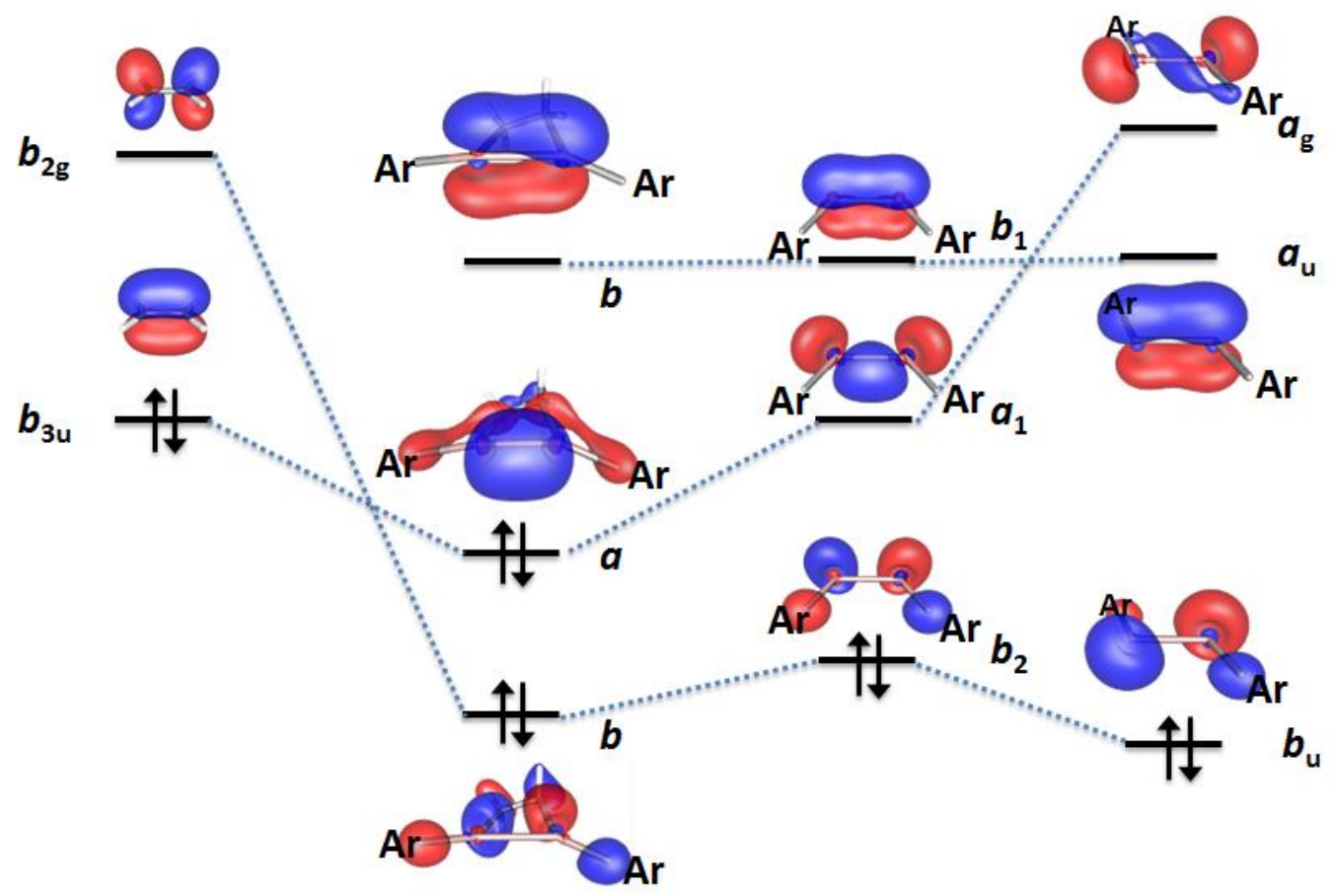

ethylene

1,2-digalla-

cis-ArGaGaAr

trans-ArGaGaAr cyclobutane

Figure 1. Key frontier orbitals of ethylene and digallene along with a schematic description of the key orbital interactions involved in the formation of the proposed 1,2digallacyclobutane intermediate. Orbital symmetries for each molecule are given according to its respective point group.

The morphologies of the key frontier orbitals involved in the formation of 1,2digallacyclobutane intermediate indicate that its formation is facile, provided that the conformation of the digallene changes readily. As shown below, the energetic penalty from the cis-trans isomerization is more than compensated by the energy released in the formation of two new Ga-C sigma bonds, making the overall reaction exergonic. Therefore, without significant steric bulk involved, this reaction can take place in a 
concerted manner and presumably even without an energy barrier. Figure 1 also shows that the addition of a second equivalent of olefin to the 1,2-digallacyclobutane intermediate is unlikely to be instantaneous as there is no straightforward way to make their frontier orbital symmetries match for a synergistic interaction.

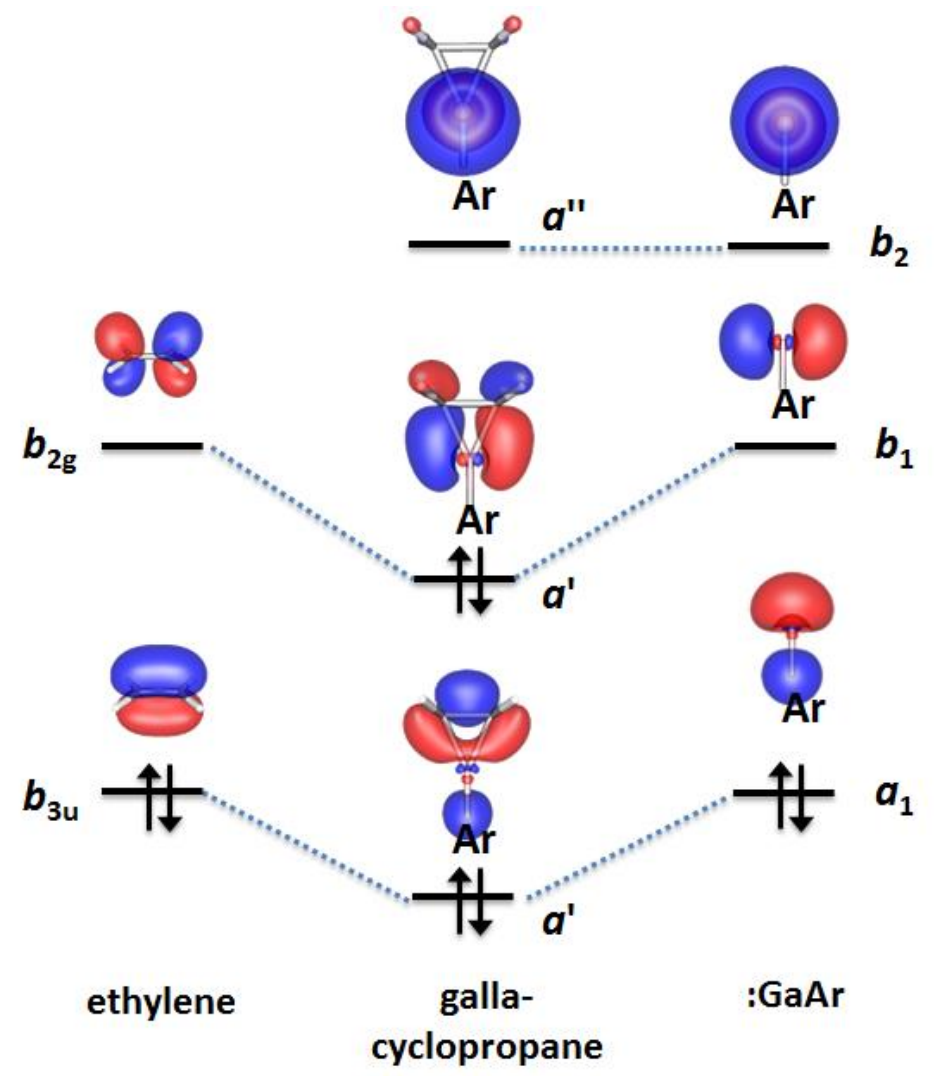

Figure 2. Key frontier orbitals of ethylene and monomeric gallanediyl along with a schematic description of the key orbital interactions involved in the formation of the proposed gallacyclopropane intermediate. Orbital symmetries for each molecule are given according to its respective point group ( $C_{2 \mathrm{v}}$ for gallanediyl).

The frontier orbitals of a monomeric gallianediyl :GaAr are shown in Figure 2 along with those of ethylene. For symmetry reasons, the formation of a gallacyclopropane intermediate requires a HOMO-HOMO interaction between ethylene and : $\mathrm{GaAr}$, along with a similar LUMO-LUMO interaction. This gives a set of four new MOs of which the lowest two become doubly occupied in agreement with the two new Ga-C linkages in the gallacyclopropane product. It should be noted here that the HOMO of the 
gallacyclopropane thus formed is much higher in energy than the HOMO of either ethylene or the monomeric diyl, which suggests that the reaction might not be spontaneous (see below). Nevertheless, the gallacyclopropane intermediate has a lowlying LUMO, which is essentially an empty p-orbital at the gallium atom. Therefore, it can be thought to undergo further reactivity with another equivalent of a monomeric :GaAr via a HOMO-LUMO type Ga-Ga interaction. The subsequent reorganization of the orbital framework then gives rise to the formation of a Ga-C bond and, consequently, to the 1,2-digallacyclobutane intermediate (see Scheme 4). The frontier orbitals shown in Figure 2, however, indicate no obvious pathway by which two equivalents of the gallacyclopropane intermediate could readily react to yield the 1,4-digallacyclohexane product directly.

Gallacyclopropane pathway. We have previously shown that with a larger terphenyl substituent $\mathrm{Ar}^{\mathrm{iPr} 8}$, the monomeric diyl form is found in the solid state and calculations have shown that it is marginally more stable also in solution. ${ }^{10}$ Thus, we hypothesized that treatment of the monomeric diyl with ethylene might allow observation of a gallacyclopropane intermediate. The monomeric species $: \mathrm{GaAr}^{\mathrm{iPr} 8}$ was dissolved in pentane and treated with an excess of ethylene gas under ambient conditions $\left(25^{\circ} \mathrm{C}, 1\right.$ atm). The solution was allowed to stir vigorously for $18 \mathrm{~h}$. No color change was observed and the : $\mathrm{GaAr}^{\mathrm{iPr} 8}$ starting material was recovered unchanged.

Calculations for the addition of olefins ethylene (a), propene (b), 1-hexene (c), and styrene (d) to a monomeric : $\operatorname{GaAr}(\mathbf{1})\left(\mathrm{Ar}=\mathrm{C}_{6} \mathrm{H}_{3}-2,6-\mathrm{Me}_{2}\right)$ were carried out to further test the feasibility of the reaction pathway implicating the :GaAr ${ }^{\mathrm{iPr} 8}$ monomer. For all olefins studied, the initial reaction on this pathway is calculated to be highly endergonic $\left(\Delta \mathrm{G}=70-90 \mathrm{~kJ} \mathrm{~mol}^{-1}\right),{ }^{23}$ which implies that it is unlikely that gallacyclopropane intermediates are involved in the formation of 1,4-digallacyclohexane products. This is in harmony with experimental results that the gallacyclopropane product does not form under ambient conditions. In addition, it provides strong support, albeit indirect, for the stepwise cycloaddition pathway and indicates that the digallenes react as dimers with olefins (via 1,2-digallacyclobutane intermediates) rather than as monomers. 
It is possible to argue that steric hindrance prevents the monomeric gallanediyl :GaAr ${ }^{\mathrm{iPr} 8}$ from reacting with olefins, and thus we attempted a similar reaction with hydrogen. Treatment of a pentane solution of the monomeric species with excess hydrogen gas under ambient conditions $\left(25^{\circ} \mathrm{C}, 1 \mathrm{~atm}\right)$ resulted in no color change after $18 \mathrm{~h}$, and the :GaAr ${ }^{\mathrm{iPr}{ }_{8}}$ was isolated unchanged, as confirmed by ${ }^{1} \mathrm{H}$ NMR spectroscopy. In contrast, $\mathrm{H}_{2}$ was observed to react readily with the digallene ${ }^{{ }^{P{ }_{r}} 4} \mathrm{ArGaGaAr}{ }^{\mathrm{iPr}}{ }_{4}$ under the same conditions. This strongly suggests that the reaction of digallenes with $\mathrm{H}_{2}$ proceeds by an addition mechanism similar to the reaction with olefins and involves solely the digallene, rather than the dissociated gallanediyl monomers. Subsequent calculations for the reaction of our model system 1 with $\mathrm{H}_{2}$ gave results that fully agree with experimental observations, although the formation of a gallium dihydride is exergonic $(\Delta \mathrm{G}=-37 \mathrm{~kJ}$ $\mathrm{mol}^{-1}$ ), the theoretical activation energy for this process is $200 \mathrm{~kJ} \mathrm{~mol}^{-1}$. Hence, reaction via monomeric gallanediyl is only expected to take place at an elevated temperature and pressure.

$[2+2+2]$ cycloaddition pathway. The $[2+2+2]$ cycloaddition pathway was examined theoretically by calculating the reactions of model digallenes, ArGaGaAr (2, $\left.\mathrm{Ar}=\mathrm{Ph} ; \mathbf{3}, \mathrm{Ar}=\mathrm{C}_{6} \mathrm{H}_{3}-2,6-\mathrm{Me}_{2}\right)$, with ethylene $(\mathbf{a})$, propene $(\mathbf{b}), 1$-hexene $(\mathbf{c})$, and styrene (d).

The calculations show that the addition of a first equivalent of olefin is instantaneous (no detectable transition state) and slightly exergonic $\left(\Delta \mathrm{G}=-30\right.$ to $\left.-60 \mathrm{~kJ} \mathrm{~mol}^{-1}\right)$ for all olefins (a-d) and for both digallenes (2 and 3) (for full details, see Supporting Information). This is fully in line with the conclusions drawn from orbital analyses which indicate that the reaction can follow a barrierless concerted pathway if no significant steric bulk is involved (see above). Successive calculations probing the addition of a second equivalent of olefin to different 1,2-digallacyclobutane intermediates showed the process to be spontaneous and concerted, like the first addition $\left(\Delta \mathrm{G}=-30\right.$ to $-80 \mathrm{~kJ} \mathrm{~mol}^{-}$

$\left.{ }^{1}\right)$. However, this reaction step always involves a low-energy transition state $\left(\Delta \mathrm{G}^{\ddagger}=40\right.$ to $80 \mathrm{~kJ} \mathrm{~mol}^{-1}$ ) in which the second equivalent of olefin interacts in an almost symmetrical fashion with one of the gallium atoms in the 1,2-digallacyclobutane intermediate. The 
transition state for the addition of ethylene (a) to the 1,2-digallacyclobutane $(\mathbf{3}+\mathbf{a})$ is shown in Figure 3 along with pertinent structural parameters.

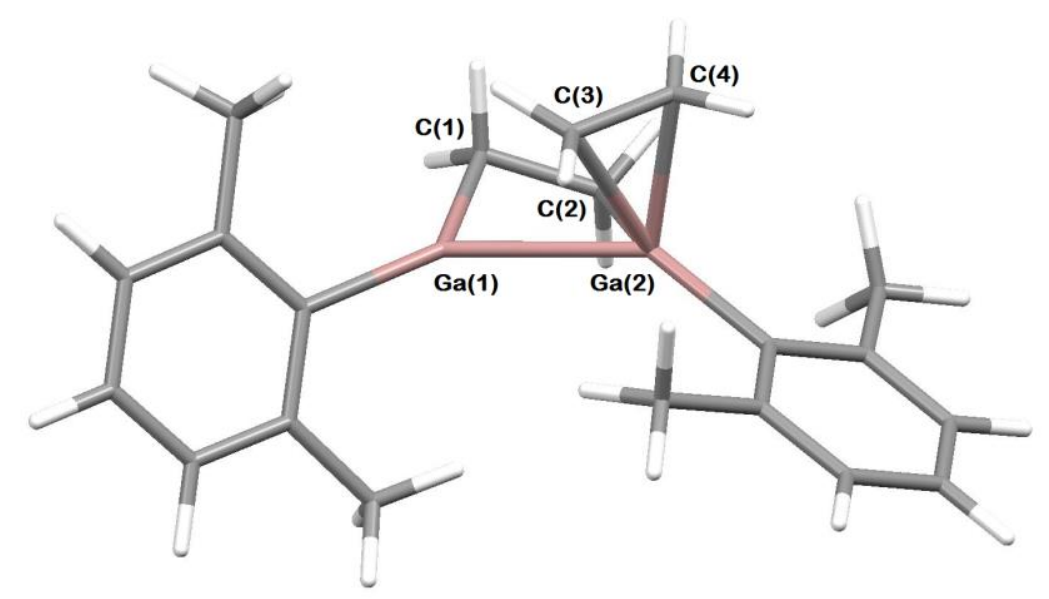

Figure 3. Calculated transition state of the addition of ethylene (a) to 1,2digallacyclobutane intermediate $(\mathbf{3}+\mathbf{a})$. Selected bond distances $(\AA)$ and angles $\left({ }^{\circ}\right)$ : $\mathrm{Ga}(1)-\mathrm{Ga}(2)$ 2.541; $\mathrm{Ga}(1)-\mathrm{C}(1)$ 2.011; $\mathrm{Ga}(2)-\mathrm{C}(2)$ 2.034; $\mathrm{C}(1)-\mathrm{C}(2)$ 1.539; $\mathrm{Ga}(2)-\mathrm{C}(3)$ 2.301; $\mathrm{Ga}(2)-\mathrm{C}(4)$ 2.229; C(3)-C(4) 1.398; C(3)-Ga(2)-C(4) 35.9; Ga(1)-Ga(2)-C(3) 66.1; $\mathrm{Ga}(1)-\mathrm{Ga}(2)-\mathrm{C}(4) 97.7$.

The interaction of a second equivalent of olefin with the 1,2-digallacyclobutane intermediate formally involves electron donation from the $\sigma$-type Ga-Ga bonding HOMO of 1,2-digallacyclobutane to the $\pi^{*}$ LUMO of the olefin (see Figure 1) as the geometry of the transition state allows the phases of these orbitals to match perfectly. However, there is no apparent interaction between the $\pi$-type Ga-Ga bonding LUMO of the digallacyclobutane and the $\pi$-type $\mathrm{C}-\mathrm{C}$ bonding $\mathrm{HOMO}$ of the olefin. This is in harmony with the modest elongation of the $\mathrm{C}=\mathrm{C}$ and $\mathrm{Ga}-\mathrm{Ga}$ bonds in the transition state structure in comparison to the free reactants. An internal reaction coordinate calculation confirmed that in each case the transition state connects to the substituted 1,4-digallacyclohexane product, which forms through reorganization of the orbital framework involving the $\mathrm{C}=\mathrm{C}$ and Ga-Ga bonds to yield two new Ga-C interactions. In light of these theoretical data, a 
stepwise and concerted double [2 +2$]$ cycloaddition mechanism appears to be a plausible explanation for the observed reactivity of the digallene $\mathrm{Ar}^{\mathrm{iPr}{ }_{4}} \mathrm{GaGaAr}{ }^{\mathrm{Pr}_{4}}$ with olefins.

Experimentally it was observed that with olefins other than ethylene, the substituents located on the six-membered ring in the 1,4-digallacyclohexane product are exclusively in a trans-orientation and at positions 2 and $5 .{ }^{13}$ Furthermore, the 1,4-digallacyclohexane product was always found to adopt the chair conformation while the stereochemistry of the trans-substituents (either axial or equatorial) depends explicitly on the identity of the olefin. The $[2+2+2]$ cycloaddition pathway offers a rationale for these findings because the stereochemistry of the product depends directly on the relative orientation of the second equivalent of olefin and the 1,2-digallacyclobutane intermediate in the transition state. The structure of the transition state (see Figure 3) supports the fact that substitution at the olefin is unlikely to involve the two carbon atoms that end up adjacent to the same gallium center in the final product (i.e. positions 2 and 6 in 1,4-digallacyclohexane) simply because of increased steric hindrance. However, the 2,5-disubstituted digallacyclohexane core has three possible regioisomers of which the transition states leading to axial-equatorial and equatorial-equatorial isomers involve the greatest and least steric hindrance, respectively. It is thus unsurprising that reactions involving smaller chain alkenes propene and 1-hexene yielded a mixture of both isomers in nearly equal amounts, whereas with styrene the extra space required to accommodate the phenyl ring led exclusively to the isomer with substituents in the equatorial positions. ${ }^{13}$

The effect of steric bulk on the $[2+2+2]$ cycloaddition pathway. The initial step of the $[2+2+2]$ cycloaddition pathway involves an attack of the olefin to the formal $\mathrm{Ga}=\mathrm{Ga}$ double bond, which necessitates a simultaneous change in the conformation of the digallene from trans to cis. With the model systems studied herein, this step is found to take place instantaneously, but with bulkier aromatic substituents on the digallene, it is likely to involve a transition state akin to the second step on the pathway. In order to test the influence of the aromatic group on the digallene to the proposed mechanism, we modeled the $[2+2+2]$ cycloaddition pathway for the reaction of two equivalents of ethylene (a) with a terphenyl substituted digallene 4, ArGaGaAr, $\mathrm{Ar}=\mathrm{C}_{6} \mathrm{H}_{3}-2,6-\mathrm{Ph}_{2}$. As predicted, the calculations showed that the increased steric bulk does not have a 
significant impact on the energetics of the second addition step $\left(\Delta \mathrm{G}^{\ddagger}=68 \mathrm{~kJ} \mathrm{~mol}^{-1} ; \Delta \mathrm{G}=\right.$ $84 \mathrm{~kJ} \mathrm{mo1}^{-1}$ ) but the first olefin addition was now found to proceed through a characterizable transition state.

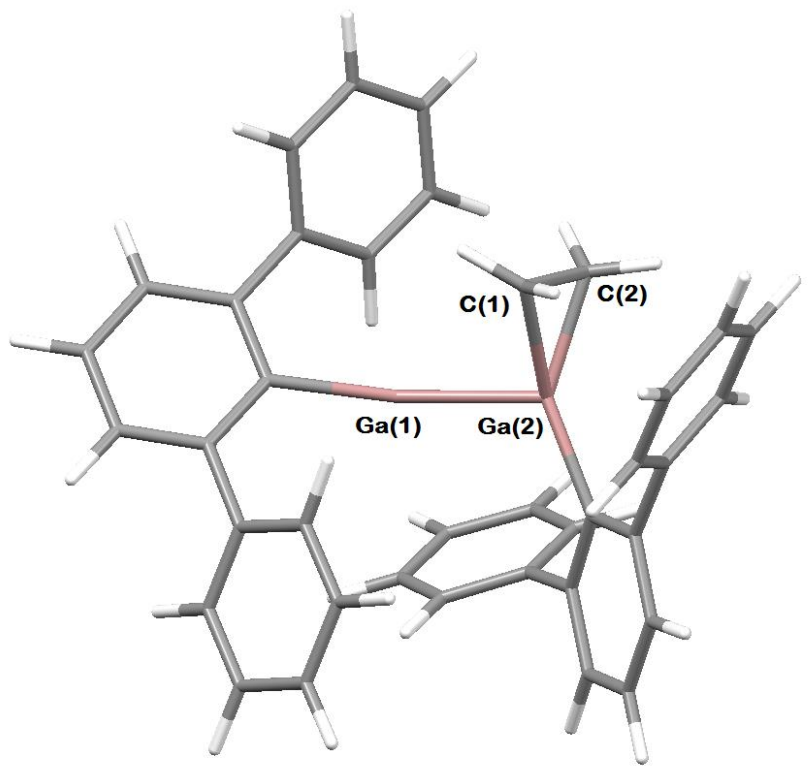

Figure 4. Calculated transition state of addition of ethylene (a) to digallene (4). Selected bond distances ( $\AA$ ) and angles $\left({ }^{\circ}\right)$ : $\mathrm{Ga}(1)-\mathrm{Ga}(2)$ 2.384; $\mathrm{Ga}(2)-\mathrm{C}(2)$ 1.999; $\mathrm{Ga}(2)-\mathrm{C}(1)$ 2.096; C(1)-C(2) 1.492; C(1)Ga(1)C(2) 42.7; Ga(1)-Ga(2)-C(2) 107.2; Ga(1)-Ga(2)-C(1) 92.1.

The transition state for the addition of ethylene to the digallene $\mathbf{4}$ is shown in Figure 4 along with pertinent structural parameters. The ethylene molecule interacts in a nearly symmetrical fashion, mainly with one of the gallium atoms (although the digallene LUMO involves both galliums, cf. Figure 1). We note that the transition state somewhat resembles a gallium diyl adduct of a gallacyclopropane, although the geometry around the $\mathrm{Ga}(2)$ center is significantly distorted from a trigonal planar towards tetrahedral. The nature of the transition state corresponds to a concerted mechanism and following the transition vector via subsequent geometry optimization led to immediate $\mathrm{Ga}(1)-\mathrm{C}(1)$ bond formation and closure of the four-membered ring to form the 1,2-digallacyclobutane intermediate $\left(\Delta \mathrm{G}=-53 \mathrm{~kJ} \mathrm{~mol}^{-1}\right)$. Interestingly, at the other end of the reaction pathway, the transition state connects to an energy minimum in which the ethylene makes a weakly 
bound adduct with the digallene in an overall similar fashion to that in the transition state. Consequently, the calculated activation energy for the first addition is very small $\left(\Delta \mathrm{G}^{*}=\right.$ $47 \mathrm{~kJ} \mathrm{mo1}^{-1}$ ) and for all practical purposes the reaction is instantaneous, in agreement with experimental observations for the reaction of $\mathrm{Ar}^{\mathrm{iPr}{ }_{4}} \mathrm{GaGaAr}^{\mathrm{iPr}{ }_{4}}$ with ethylene.

Figure 4 suggests how protected the reactive site of the molecule, the Ga-Ga bond, would be when using more realistic model systems. With the parent terphenyl ligand as a substituent, the closest distance measured between aromatic $\mathrm{C}-\mathrm{H}$ hydrogens and hydrogens on the ethylene molecule is just over $2.5 \AA$. For the experimentally characterized system, $\mathrm{Ar}^{\mathrm{iPr}}{ }_{4} \mathrm{GaGaAr}^{\mathrm{iPr} r_{4}}$, the steric bulk at the terphenyl moieties is substantially increased. Consequently, the reactivity of the digallene will most likely be blocked if sterically encumbered olefins are used. This is fully in line with experimental results, which showed that under ambient conditions, $\mathrm{Ar}^{\mathrm{iPr}{ }_{4}} \mathrm{GaGaAr}^{\mathrm{iPr}{ }_{4}}$ reacts only with small terminal olefins.

Diradical mechanism. As an alternative to the concerted $[2+2+2]$ cycloaddition pathway discussed above, we considered a stepwise radical addition for the addition of olefins (a-d) to the model digallenes (1 and 2). Consequently, the singlet potential energy surfaces of the reaction intermediates were rescanned using the broken symmetry formalism which is capable of modeling singlet diradical species that have their radical sites at two different nuclei. ${ }^{18}$ However, the calculations resulted in the diradical determinants $\left(S^{2}=1\right)$ reverting to a closed shell potential energy surface as pure singlets $\left(S^{2}=0\right)$ were in all cases found to be lower in energy. Furthermore, tests for internal instabilities in the Kohn-Sham determinants of all stationary points involved in the concerted pathway were negative, supporting the conclusion that the reactivity of the digallenes studied herein proceeds via two electron transfer steps or involves diradical character which is less than that observable at the DFT level of theory.

Addition of hydrogen to digallenes. Since it was shown by both experiment and theory that monomeric gallanediyls do not react readily with $\mathrm{H}_{2}$ (see above), we conducted a computational mechanistic study using the terphenyl substituted model digallene $\mathbf{4}$ as the reactive species. The investigation of the potential energy surface study was initiated by examining the reaction of one equivalent of $\mathrm{H}_{2}$ with 4. The results showed that the 
reaction is exergonic $\left(\Delta \mathrm{G}=-65 \mathrm{~kJ} \mathrm{~mol}^{-1}\right)$ and proceeds through a transition state $\left(\Delta \mathrm{G}^{\ddagger}=\right.$ $\left.98 \mathrm{~kJ} \mathrm{~mol}^{-1}\right)$ wherein the hydrogen molecule is significantly stretched $(\mathrm{r}(\mathrm{H}-\mathrm{H})=1.129 \AA$ ) and interacts with both of the gallium atoms in the digallene (see Figures 5 and 6). A closer inspection of the key frontier molecular orbitals of the transition state reveals a synergistic donor-acceptor interaction: the first interaction is formed between the $\sigma$-type Ga-Ga LUMO of the digallene and the $\sigma$-type $\mathrm{HOMO}$ of $\mathrm{H}_{2}$ (Figure 5a, left), whereas the second interaction takes place between the $\mathrm{n}_{\mathrm{p}}$-type lone-pair HOMO of the digallene and the $\sigma^{*}$-type LUMO of $\mathrm{H}_{2}$ (Figure 5a, right) By following the transition state vector via an intrinsic reaction coordinate calculation, it was confirmed that this reaction step yields the 1,2-disubstituted digallene, $\operatorname{Ar}(\mathrm{H}) \mathrm{GaGa}(\mathrm{H}) \mathrm{Ar}$, as the end product.

a)

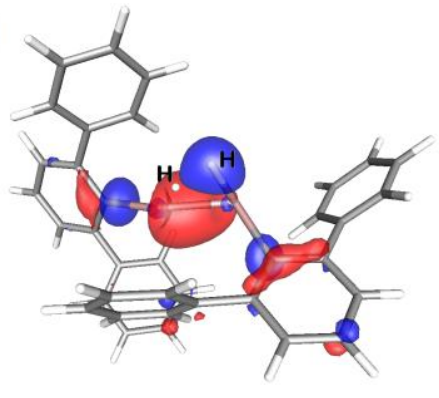

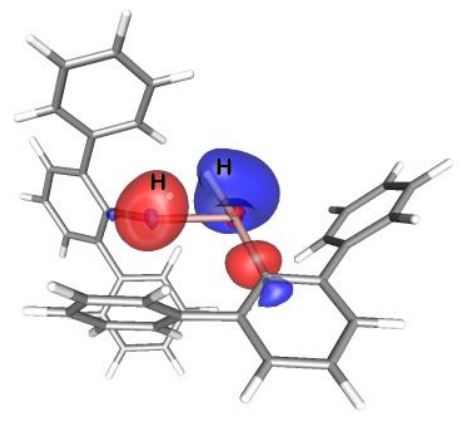

b)

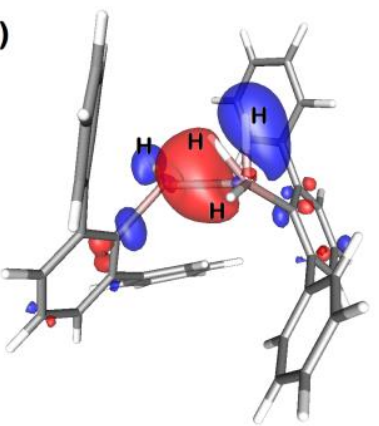

Figure 5. Visualization of the key orbital interactions in the transition states involved in the addition of (a) first and (b) second equivalent of $\mathrm{H}_{2}$ to digallene 4 .

It was observed that the 1,2-isomer can easily convert to the slightly less stable ( $\Delta \mathrm{G}=25$ $\left.\mathrm{kJ} \mathrm{mol}^{-1}\right)$ 1,1-isomer $\operatorname{Ar}(\mathrm{H})_{2} \mathrm{GaGaAr}$ via simple hydride transfer $\left(\Delta \mathrm{G}^{\ddagger}=58 \mathrm{~kJ} \mathrm{~mol}^{-1}\right.$; Figure 6). However, we were unable to identify any mechanism for the direct formation of the 1,1-isomer from the reaction of $\mathbf{4}$ with one equivalent of $\mathrm{H}_{2}$, which contrasts the reactivity observed for the related digermynes and distannynes that gave both isomers via two competitive pathways. ${ }^{7}$

Since the addition of a second equivalent of $\mathrm{H}_{2}$ to the digallene can in principle involve either the 1,1- or 1,2-isomer, both of these possibilities were thoroughly examined through calculations. However, the 1,2-isomer is thermodynamically slightly favored over the 1,1-isomer, which suggests that it is likely to be the reactive species. Indeed, 
despite numerous attempts, no transition state could be identified for the reaction of the 1,1-isomer with a second equivalent of $\mathrm{H}_{2}$. In contrast, the 1,2-isomer reacts readily with $\mathrm{H}_{2}$ to give a transition state $\left(\Delta \mathrm{G}^{*}=140 \mathrm{~kJ} \mathrm{~mol}^{-1}\right)$ that leads to cleavage of the $\mathrm{Ga}-\mathrm{Ga}$ bond and the formation of two molecules of gallium dihydride, $\mathrm{ArGaH}_{2}$, which interact and dimerize spontaneously and without energy barrier to form the experimentally characterized end product, the bridged species $\operatorname{Ar}(\mathrm{H}) \mathrm{Ga}(\mu-\mathrm{H})_{2} \mathrm{Ga}(\mathrm{H}) \operatorname{Ar}(\Delta \mathrm{G}=-21 \mathrm{~kJ}$ $\left.\mathrm{mol}^{-1}\right)$.

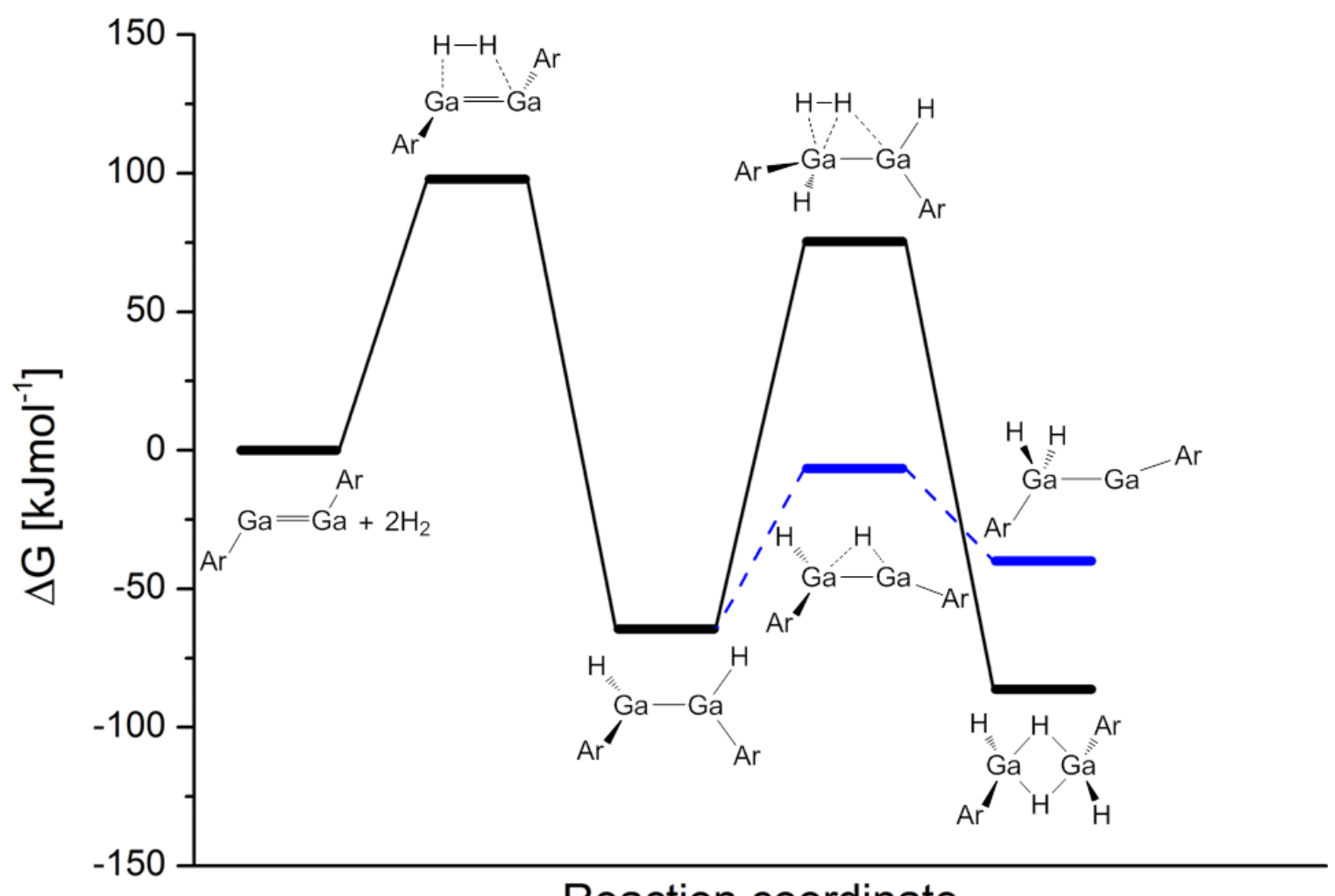

Figure 6. Free energy diagram for the reaction of digallenes with two equivalents of $\mathrm{H}_{2}$ $\left(\mathrm{Ar}=\mathrm{C}_{6} \mathrm{H}_{3}-2,6-\mathrm{Ph}_{2}\right)$. The blue pathway shows the isomerization of $\operatorname{Ar}(\mathrm{H}) \mathrm{GaGa}(\mathrm{H}) \mathrm{Ar}$ to $\operatorname{Ar}(\mathrm{H})_{2} \mathrm{GaGaAr}$ with no further reactivity.

The reactivity of the 1,2-isomer with $\mathrm{H}_{2}$ can be rationalized by investigating the frontier orbitals of its transition state which show only one donor-acceptor interaction between the $\sigma$-type HOMO of the digallene and the $\sigma^{*}$-type LUMO of $\mathrm{H}_{2}$ (Figure $5 b$ ); there is no identifiable interaction between the $\pi$-type LUMO of the digallene and the $\sigma$-type 
HOMO of $\mathrm{H}_{2}$. However, following the intrinsic reaction coordinate towards products shows that a reorganization of the orbital framework takes place, leading to the formation of two $\mathrm{Ga}-\mathrm{H}$ bonds via transfer of electrons from the $\mathrm{Ga}-\mathrm{Ga}$ bond to one of the hydrogen atoms (formally $\mathrm{H}^{+}$) and from the $\sigma$-bond of $\mathrm{H}_{2}$ (formally $\mathrm{H}^{-}$) to the second gallium center (cf. the reaction of 1,2-digallacyclobutane intermediates with the second equivalent of olefin). These data can be compared to the frontier orbitals of the 1,1isomer, which immediately reveals a reason for why it was not found to have any reactivity with $\mathrm{H}_{2}$ : the 1,1-isomer has both hydrogen atoms connected to the same gallium center and, consequently, its HOMO is no longer of proper symmetry to allow the second equivalent of $\mathrm{H}_{2}$ to form a donor-acceptor interaction with the two-coordinate gallium center.

The reluctance of the 1,1-isomer $\operatorname{Ar}(\mathrm{H})_{2} \mathrm{GaGaAr}$ to react with an additional equivalent of $\mathrm{H}_{2}$ is in sharp contrast to the chemistry of the related digermynes $\operatorname{Ar}(\mathrm{H})_{2} \mathrm{GeGeAr}$ that were found to react exclusively through this intermediate. ${ }^{7}$ However, it should be noted that there is a difference of two valence electrons between these compounds, which means that their frontier orbitals are necessarily different. Specifically, the germanium analogue has one lone pair of electrons at the two-coordinate germanium atom, which is not present in the digallene. Hence, the facile low-energy $\left(\Delta \mathrm{G}^{\ddagger}=91 \mathrm{~kJ} \mathrm{~mol}^{-1}\right)$ barrier calculated for the reaction of $\operatorname{Ar}(\mathrm{H})_{2} \mathrm{GeGeAr}$ with $\mathrm{H}_{2}$ can be understood in terms of synergistic orbital interactions. In contrast, there is no lone pair in the 1,1-isomer of the digallene, which means that the reaction proceeds via the 1,2-isomer $\operatorname{Ar}(\mathrm{H}) \mathrm{GaGa}(\mathrm{H}) \mathrm{Ar}$. Furthermore, since the transition state is in this case characterizable by only one donoracceptor interaction, the calculated activation energy for the second addition is necessarily slightly higher than the first (see Figure 6).

The final product from the reaction of digallenes with hydrogen is the bridged species $\operatorname{Ar}(\mathrm{H}) \mathrm{Ga}(\mu-\mathrm{H})_{2} \mathrm{Ga}(\mathrm{H}) \mathrm{Ar}$ whose bonding is analogous to that in the parent digallene, $\mathrm{Ga}_{2} \mathrm{H}_{6}$, and can be considered to involve two 3-center 2-electron bonds. Experimentally, only the trans-isomer has been characterized by X-ray crystallography. ${ }^{12}$ Our calculations for the potential energy surface showed that, depending on the relative orientation of the second equivalent of $\mathrm{H}_{2}$ and the 1,2-isomer in the transition state, both cis- and trans- 
products could be obtained. However, the transition state leading to the trans-product is slightly $\left(16 \mathrm{~kJ} \mathrm{~mol}^{-1}\right)$ more favorable in energy, indicating that it should be the major product. In addition, the cis- and trans-products can readily interconvert via a low-energy transition state $\left(\Delta \mathrm{G}^{\ddagger}=44 \mathrm{~kJ} \mathrm{~mol}^{-1}\right)$.

Implications for the chemistry of putative dialuminenes. The mechanism of the reaction of digallenes with ethylene is reminiscent of the room reductive coupling of an aluminum diodide precursor $\mathrm{Ar}^{\mathrm{iPr}_{4}} \mathrm{AlI}_{2}$ in the presence of alkyne $\mathrm{Me}_{3} \mathrm{SiCCSiMe}_{3}{ }^{24}$ This reaction yields 1,2-dialuminacyclobutene, $\left(\mathrm{Ar}^{\mathrm{iPr}}{ }^{4} \mathrm{Al}\right)_{2}\left(\mathrm{CSiMe}_{3}\right)_{2}, \quad$ as the crystallographically characterized end product. The exact mechanism of the transformation has not been reported, but the reaction was experimentally observed to involve the known $\mathrm{Al}-\mathrm{Al}$ bonded species $\mathrm{Ar}^{\mathrm{iPr} 4}(\mathrm{I}) \mathrm{AlAl}(\mathrm{I}) \mathrm{Ar}^{\mathrm{iPr}}{ }^{25}$ Based on the theoretical results discussed herein, it is straightforward to envisage how a reduction of this intermediate with $\mathrm{KC}_{8}$, followed by elimination of $\mathrm{KI}$, could yield the dialuminene $\mathrm{Ar}^{\mathrm{iPr} 4} \mathrm{AlAlAr}{ }^{\mathrm{iPr} 4}$ which is then expected to undergo a rapid cycloaddition with the alkyne to give the end product.

We showed earlier that the putative dialuminene $\mathrm{Ar}^{\mathrm{iPr}}{ }_{4} \mathrm{AlAlAr}{ }^{\mathrm{iPr}}{ }_{4}$, when prepared without the presence of the alkyne, reacts with the solvent (toluene) to yield a cycloaddition product whose structure has been unequivocally confirmed by X-ray crystallography. ${ }^{25}$ The mechanism of this reaction was initially suggested to proceed in [2+2] manner, involving the electrons in the slipped $\pi$-type orbital on the dialuminene. However, simple cycloadditions involving toluene are extremely rare. Furthermore, none of the heavier dimetallenes show any evidence of similar reactivity with toluene. In this respect, we have recently shown through high-level quantum chemical calculations that the ground states of dialuminenes are unique in the series as they have noticeable singlet diradical character. ${ }^{11}$ Consequently, the reactivity of $\mathrm{Ar}^{\mathrm{iPr}{ }_{4}} \mathrm{AlAlAr}{ }^{\mathrm{iPr} 4}$ with toluene can be explained by this route, as cycloaddition of photochemically generated singlet oxygen to conjugated arenes is well documented in the literature. ${ }^{26}$ This prompted us to conduct preliminary calculations for the reactivity of the model dialuminene $\operatorname{ArAlAlAr}\left(\mathbf{5}, \mathrm{Ar}=\mathrm{C}_{6} \mathrm{H}_{3}-2\right.$,6$\mathrm{Me}_{2}$ ), with one equivalent of simple olefins ethylene and propene. 
The reaction of $\mathbf{5}$ with ethylene was found to be spontaneous and barrierless as was the case also for its gallium analogue. However, when using propene as the olefin, the reaction was found to proceed via a transition state with a dangling $\mathrm{H}_{3} \mathrm{CC}(\mathrm{H}) \mathrm{C}(\mathrm{H})_{2}$ moiety. Subsequent stability analysis showed that the Kohn-Sham determinant has a restricted-unrestricted instability $\left(S^{2}=0.315\right)$, indicative of a broken symmetry, diradicaloid, ground state, which assigns unpaired spin density to the dicoordinate $\mathrm{Al}(1)$ center $(-0.47)$ as well as to the $\mathrm{Al}(2)$ atom $(+0.25)$ and the $\mathrm{C}(2)$ carbon at the dangling olefin (+0.27). High-level single point complete active space (CAS) calculation using an active space of four electrons and four orbitals confirmed the open shell nature of the transition state as it assigned as much as 0.23 electrons to the first formally empty orbital within the active space. Typically, natural orbital occupations higher than 0.10 electrons are considered as an indication of multiconfigurational character of the wave function. ${ }^{27}$ Hence, these results demonstrate that the reactivities of dialuminenes are more complex than that of the corresponding digallenes and they are also more likely to involve open shell, radical-type, mechanisms.

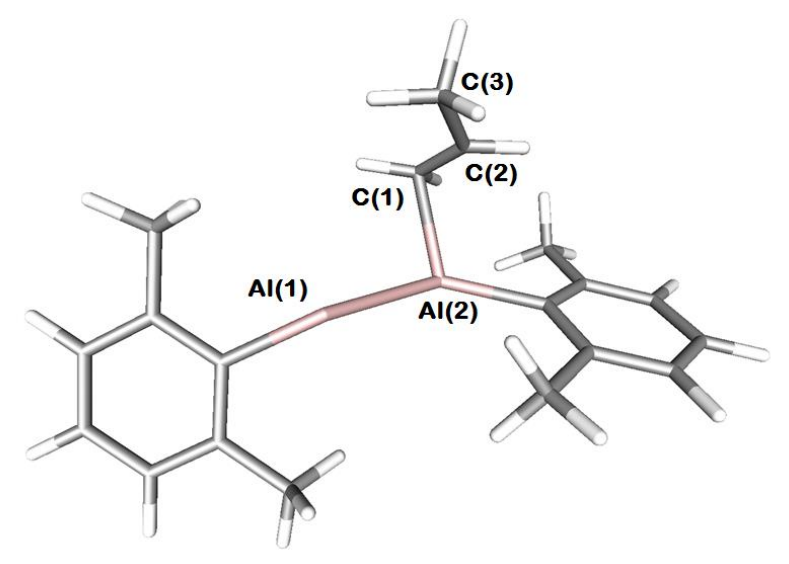

Figure 7. Calculated transition state of addition of propene (b) to dialuminene (5). Selected bond distances $(\AA)$ and angles $\left(^{\circ}\right)$ : $\mathrm{Al}(1)-\mathrm{Al}(2)$ 2.523; $\mathrm{Al}(2)-\mathrm{C}(1)$ 2.204; $\mathrm{Al}(2)$ $\mathrm{C}(2)$ 2.493; C(1)-C(2) 1.378; $\mathrm{Al}(2)-\mathrm{C}(1)-\mathrm{C}(2)$ 84.8; $\mathrm{Al}(1)-\mathrm{Al}(2)-\mathrm{C}(1)$ 102.0; $\mathrm{Al}(1)-\mathrm{Al}(2)-$ C(2) 102.3 .

\section{Conclusions}


The mechanistic pathway for the addition of olefins to a dimeric digallene was determined to proceed via a stepwise double [2 +2$]$ cyclization reaction first forming a short lived 1,2-digallacyclobutane intermediate which immediately reacts with a second equivalent of olefin to give the 1,4-digallacyclohexane product. Both steps possess small activation barriers and can be considered to occur instantaneously. The reactivity shuts down, however, due to steric hindrance in the case of internal olefins. Contrary to steric expectations, the reaction of gallanediyl monomers with olefins does not proceed readily under ambient conditions, confirming that the formation of the proposed gallacyclopropane intermediate is not favored.

Similarly, we showed experimentally that the gallanediyl monomer does not readily react with $\mathrm{H}_{2}$ under ambient conditions. The formation $\mathrm{ArGaH}_{2}$ species was calculated to be thermodynamically favored; the lack of reactivity under ambient conditions can be justified by the calculation of an activation energy of almost $200 \mathrm{~kJ} \mathrm{~mol}^{-1}$ for this transformation.

Investigation of the mechanism of the formation of the observed product in the reaction of digallene with excess $\mathrm{H}_{2}$ indicated that this reaction likely proceeds by initial reaction of a first equivalent of $\mathrm{H}_{2}$ with digallene in a 1,2-fashion (formation of the 1,1-dihyride by isomerization is possible, though it is a dead-end pathway). This is followed by reaction with a second equivalent of $\mathrm{H}_{2}$ (again in a 1,2 fashion) to form a species that undergoes Ga-Ga bond scission to give a short-lived $\mathrm{ArGaH}_{2}$ intermediate. Reassociation of the monomeric $\mathrm{ArGaH}_{2}$ fragments leads to the observed thermodynamically favored product, $\operatorname{Ar}(\mathrm{H}) \mathrm{Ga}(\mu-\mathrm{H})_{2} \mathrm{Ga}(\mathrm{H}) \mathrm{Ar}$.

Initial calculations of the reaction of a dialuminene with propene showed that, in contrast to the digallenes, it proceeds by an open-shell diradicaloid intermediate, consistent with the higher singlet diradical character of the aluminum derivative. 


\section{ASSOCIATED CONTENT}

\section{Supporting Information Available:}

Calculated relative energies, optimized coordinates (in xyz-format) and the full reference 17. This material is available free of charge via the Internet at http://pubs.acs.org.

\section{AUTHOR INFORMATION}

\section{Corresponding Authors}

Philip P. Power: Fax: +1-530-732-8995; Tel: +1-530-752-8900; E-mail: pppower@ucdavis.edu

Heikki M. Tuononen: Fax: +358-14-260-2501; Tel: +358-45-235-8588; E-mail: heikki.m.tuononen@jyu.fi

Notes: The authors declare no competing financial interests.

ACKNOWLEDGEMENTS: We thank the U. S. Department of Energy (DE-FG0207ER46475) and the Academy of Finland for their support of this work. C. A. C. is grateful to NSERC of Canada for a post-doctoral fellowship.

\section{REFERENCES}

(1) Spikes, G. H.; Fettinger, J. C.; Power, P. P. J. Am. Chem. Soc. 2005, 127, 1223212233.

(2) (a) Welch, G. C.; Juan, R. R. S.; Masuda, J. D.; Stephan, D. W. Science 2006, 314, 1124-1126, (b) McCahill, J. S. J.; Welch, G. C.; Stephan, D. W. Angew. Chem. Int. Ed. 2007, 46, 4968-4971, (c) Stephan, D. W.; Erker, G. Angew. Chem. Int. Ed. 2010, 49, 4676.

(3) Frey, G. D.; Lavallo, V.; Donnadieu, B.; Schoeller, W. W.; Bertrand, G. Science 2007, 316, 539-541.

(4) (a) Peng, Y.; Guo, J.-D.; Ellis, B. D.; Zhu, Z.; Fettinger, J. C.; Nagase, S.; Power, P. P. J. Am. Chem. Soc. 2009, 131, 16272-16282, (b) Peng, Y.; Wang, C.; Fettinger, J. C.; Power, P. P. Chem. Commun. 2010, 46, 943-945.

(5) Li, J.; Schenk, C.; Goedecke, C.; Frenking, G.; Jones, C. J. Am. Chem. Soc. 2011, $133,18622-18625$.

(6) (a) Senger, S.; Radom, L. J. Am. Chem. Soc. 2000, 122, 2613-2620, (b) Senger, S.; Radom, L. J. Phys. Chem. A 2000, 104, 7375-7389, (c) Berkessel, A.; Schubert, T. J. S.; Muller, T. N. J. Am. Chem. Soc. 2002, 124, 8693-8698, (d) Chan, B.; Radom, L. Aust. J. Chem. 2004, 57, 659-663, (e) Chan, B.; Radom, L. J. Am. Chem. Soc. 2005, 127, 2443- 
2454, (f) Chan, B.; Radom, L. J. Am. Chem. Soc. 2006, 128, 5322-5323, (g) Guo, Y.; Li, S. Inorg. Chem. 2008, 47, 6212-6219, (h) Rokob, T. A.; Hamza, A.; Stirling, A.; Soós, T.; Pápai, I. Angew. Chem. Int. Ed. 2008, 47, 2435-2438, (i) Pyykko, P.; Wang, C. Phys. Chem. Chem. Phys. 2010, 12, 149-155, (j) Duarte, F.; Toro-Labbé, A. J. Phys. Chem. A 2011, 115, 3050-3059, (k) Camaioni, D. M.; Ginovska-Pangovska, B.; Schenter, G. K.; Kathmann, S. M.; Autrey, T. J. Phys. Chem. A 2012, 116, 7228-7237, (1) Wang, Z.-X.; Zhao, L.; Lu, G.; Li, H.; Huang, F. Top. Curr. Chem. 2012, 1-36.

(7) Zhao, L.; Huang, F.; Lu, G.; Wang, Z.-X.; Schleyer, P. v. R. J. Am. Chem. Soc. 2012, 134, 8856-8868.

(8) For an overview of low-valent group 13 metal chemistry, including multiple-bonded species, see: Jones, C.; Stasch, A. The Group 13 Metals Aluminum, Gallium, Indium, and Thallium: Chemical Patterns and Peculiarities, Eds. Aldridge, S.; Downs, A. J; Wiley: Chichester, 2011. Chapter 5.

(9) Hardman, N. J.; Wright, R. J.; Phillips, A. D.; Power, P. P. J. Am. Chem. Soc. 2003, $125,2667-2679$.

(10) Zhu, Z.; Fischer, R. C.; Ellis, B. D.; Rivard, E.; Merrill, W. A.; Olmstead, M. M.; Power, P. P.; Guo, J. D.; Nagase, S.; Pu, L. Chem. Eur. J. 2009, 15, 5263-5272.

(11) Moilanen, J.; Power, P. P.; Tuononen, H. M. Inorg. Chem. 2010, 49, 10992-11000.

(12) Zhu, Z.; Wang, X.; Peng, Y.; Lei, H.; Fettinger, J. C.; Rivard, E.; Power, P. P. Angew. Chem. Int. Ed. 2009, 48, 2031-2034.

(13) Caputo, C. A.; Zhu, Z.; Brown, Z. D.; Fettinger, J. C.; Power, P. P. Chem. Commun. 2011, 47, 7506-7508.

(14) Throughout the text the IUPAC formalism for cycloaddition reactions has been used as follows: $[i+j+\ldots]$ where $i, j$ and $\ldots$ are number of electrons involved. When only one atom is involved and the electrons are in a lone pair, the type or orbital involved has been specified. i.e. $\left[4_{\pi}+2_{\sigma}\right]$. This was not done throughout, as it is often not clear from which orbital the electrons are originating in some of our cycloaddition reactions.

(15) Similar trend has also been observed for the neutral carbene analogues of group 13 elements. See Schoeller, W. W. Inorg. Chem. 2011, 50, 2629-2633.

(16) (a) Perdew, J. P.; Burke, K.; Ernzerhof, M. Phys. Rev. Lett. 1996, 77, 3865-3868, (b) Perdew, J. P.; Ernzerhof, M.; Burke, K. J. Chem. Phys. 1996, 105, 9982-9985, (c) Perdew, J. P.; Burke, K.; Ernzerhof, M. Phys. Rev. Lett. 1997, 78, 1396, (d) Adamo, C.; Barone, V. J. Chem. Phys. 1999, 110, 6158-6170.

(17) Schaefer, A.; Huber, C.; Ahlrichs, R. J. Chem. Phys. 1994, 100, 5829-5836.

(18) (a) Noodleman, L.; Norman, J. G. J. Chem. Phys. 1979, 70, 4903-4907, (b) Norman, J. G.; Ryan, P. B.; Noodleman, L. J. Am. Chem. Soc. 1980, 102, 4279-4282, (c) Noodleman, L. J. Chem. Phys. 1981, 74, 5737-5742.

(19) Frisch, M. J. et al. Gaussian 09, Revision A.1, Gaussian Inc.: Wallingford CT, 2009. For a full citation of this reference, see Supporting Information.

(20) (a) Laaksonen, L. J. Mol. Graph. 1992, 10, 33-34, (b) Bergman, D. L.; Laaksonen, L. J. Mol. Graph. Model. 1997, 15, 301-306.

(21) Caputo, C. A.; Guo, J.-D.; Nagase, S.; Fettinger, J. C.; Power, P. P. J. Am. Chem. Soc. 2012, 134, 7155-7164.

(22) (a) Becerra, R.; Walsh, R. J. Organomet. Chem. 2001, 636, 49-55, (b) Becerra, R.; Boganov, S. E.; Egorov, M. P.; Faustov, V. I.; Promyslov, V. M.; Nefedov, O. M.; Walsh, R. Phys. Chem. Chem. Phys. 2002, 4, 5079-5087, (c) Becerra, R.; Walsh, R. 
Phys. Chem. Chem. Phys. 2002, 4, 6001-6005, (d) Huck, L. A.; Leigh, W. J. Organometallics 2009, 28, 6777-6788, (e) Billone, P. S.; Beleznay, K.; Harrington, C. R.; Huck, L. A.; Leigh, W. J. J. Am. Chem. Soc. 2011, 133, 10523-10534, (f) Sen, S. S.; Khan, S.; Kratzert, D.; Roesky, H. W.; Stalke, D. Eur. J. Inorg. Chem. 2011, 1370-1373, (g) Sun, L.; Jin, G.; Feng, W.; Lu, P.; He, M.; Xie, J. J. Organomet. Chem. 2011, 696, 841-845.

(23) We note that styrene was found to react exothermally with monomeric :GaAr in calculations. However, in this case the gallium atom adds across the terminal $=\mathrm{CH}_{2}$ moiety and the aromatic ring to generate a five-membered heterocycle.

(24) Cui, C.; Li, X.; Wang, C.; Zhang, J.; Cheng, J.; Zhu, X. Angew. Chem. Int. Ed. 2006, 45, 2245-2247.

(25) Wright, R. J.; Phillips, A. D.; Power, P. P. J. Am. Chem. Soc. 2003, 125, 1078410785.

(26) Wasserman, H. H.; Murray, R. W., Singlet Oxygen. Academic Press: New York; London, 1979.

(27) (a) Pulay, P.; Hamilton, T. P. J. Chem. Phys. 1988, 88, 4926-4933, (b) Bofill, J. M.; Pulay, P. J. Chem. Phys. 1989, 90, 3637-3646, (c) Wolinski, K.; Pulay, P. J. Chem. Phys. 1989, 90, 3647-3659. 